\title{
Imaging Features, Differential Diagnosis and Management of Leiomyosarcomas: Case Series and Review of the Literature \\ Stramare $\mathbf{R}^{1}$, Orsatti $\mathbf{G}^{1 *}$, Attar $\mathbf{S}^{1}$, Rastrelli $\mathbf{M}^{2}$, Brunello $\mathbf{A}^{3}$, Bortolanza $\mathbf{C}^{1}$, Ortolan $\mathbf{P}^{1}$ and Coran $\mathbf{A}^{4}$
}

${ }^{1}$ Department of Medicine, Radiology Section, University of Padua, Padua, Italy

${ }^{2}$ Melanoma and Soft tissue Sarcoma Group, Veneto Oncological Institute IOV-IRCCS, Padua, Italy

${ }^{3}$ Medical Oncology Unit 1, Istituto Oncologico Veneto IOV-IRCCS, Padova, Italy

${ }^{4}$ Oncological Radiology Unit, Veneto Institute of Oncology IOV-IRCCS, Padua, Italy

\begin{abstract}
Leiomyosarcoma (LMS) is a relatively rare malignant tumor showing smooth-muscle differentiation and accounting for $7-10 \%$ of all soft tissue tumors (STTs). LMS occurs most commonly in retroperitoneum and extremities but can potentially involve every site of the body. Diagnosis is finally provided by a histological examination; nevertheless multiplanar imaging can suggest a radiological diagnosis of soft tissue sarcoma prior to biopsy and allow a precise assessment of primary tumor extent and systemic spreading. Computerized tomography (CT) is often the first imaging modality assessment especially for abdominopelvic LMSs and also the cornerstone of staging. CT usually shows a large, heterogeneous and unspecific mass with central areas of hemorrhage or necrosis and peripheral contrast enhancement. Magnetic resonance imaging (MRI) findings are not specific and show a nonfatty mass iso-intense to skeletal muscle on T1-weighted images and high-signal in T2-weighted images with a decreasing rim-to-center pattern of enhancement after gadolinium administration. Imaging also helps in differential diagnosis that mainly concern other STT, gastrointestinal stromal tumors (GISTs), primitive neuroendocrine tumors (PNETs), and lymphomas. Prognosis of LMS is poor and patients should be referred to hospitals with extensive experience in managing sarcomas using multidisciplinary therapeutic approach including surgery, chemotherapy and radiotherapy. The aim of this review is to underline the most important radiological features that could indicate a diagnosis of LMS and in particular to draw the attention to LMSs of the limbs as one of the most frequent location even if often overlooked in literature.
\end{abstract}

Keywords: Computerized tomography; Leiomyosarcoma; Soft tissue tumors; Gastrointestinal stromal tumors; Primitive neuroendocrine tumors

\section{Introduction}

Soft tissue sarcomas (STSs) are rare cancers with mesenchymal differentiation that account for $1 \%$ of all malignancies. Leiomyosarcoma (LMS) is a malignant tumor composed of cells showing distinct smoothmuscle differentiation $[1,2]$ and constitutes the second most common STS subtype after liposarcoma, accounting for about $7-10 \%$ of all STS $[3,4]$. In general soft tissue masses are more frequently benign, but STSs with smooth muscle differentiation often display malignant features, with LMSs being usually usually high-grade malignancy neoplasms $[5,6]$.

Incidence of LMS is decreasing because of reclassification of some gastric leiomyosarcomas as gastrointestinal stromal tumors (GIST), provided by immunohistochemistry showing expression of CD34 and c-kit $[7,8]$. LMSs occur mainly in middle-aged to older adults (5th and 6th decades of life) and can arise from different anatomic sites; the most common is the retroperitoneum (20-75\% of cases), followed by peripheral soft tissues (12-41\%), most frequently in low extremities ; the remainders can involve skin, vessels, head and neck region, trunk, bone, gastrointestinal (non GIST) and genitourinary tract $[9,10]$. It should be also acknowledged that among women about $40 \%$ of LMSs originate from the uterus [11]. Moreover, there are several case reports in the literature describing extremely rare primary locations such as the thyroid gland [12-15], gallbladder [16-18], base of tongue [19,20], liver $[21,22]$, bronchus [23], kidney [24,25] and pancreas [26,27].

According to the French Sarcoma Group's study there are two main categories of LMS, retroperitoneal and peripheral LMS that have both different clinical outcomes and molecular clusters with activation of different biologic pathways [28]. In particular, retroperitoneal LMSs overexpress genes involved in smooth muscle differentiation, are more common in women and have a poor prognosis, whereas non-retroperitoneal LMSs show overexpression of genes involved in extracellular matrix, wounding, and adhesion pathways, are predominating in men and have a better outcome [29]. Nowadays an etiopathological cause has not been identified yet; however, several risk factors have been associated with STSs development (Table 1).

Between January 2012 and November 2015, at our department 50 patients were newly diagnosed with LMS, accounting for $10 \%$ of all diagnosis of soft tissue sarcomas. Regarding tumor sites, despite the higher prevalence of retroperitoneal LMS reported in literature in our experience the most common sites were the limbs, accounting for $56 \%$ of the total (50\% lower limbs and $6 \%$ upper limbs), followed by retroperitoneum (32\%), genitourinary tract (6\%) and other localizations (6\%). LMSs of the limbs are poorly reported in literature and are not meant to be the most frequent among these tumors; nevertheless, according to Gambarotti et al. [4], extremities are the most common site of onset. In our clinical records we found the same results; therefore whenever soft tissue masses of the limbs are firstly found, we suggest that a diagnosis of LMS should be taken into account hence it should not be overlooked.

*Corresponding author: Orsatti G, Department of Medicine, Radiology Section, University of Padua, Padua, Italy, Tel: 00393498441412; E-mail: giovanna_orsatti@hotmail.it

Received February 22, 2016; Accepted April 20, 2016; Published April 22, 2016

Citation: Stramare R, Orsatti G, Attar S, Rastrelli M, Brunello A (2016) Imaging Features, Differential Diagnosis and Management of Leiomyosarcomas: Case Series and Review of the Literature. J Cancer Sci Ther 8: 084-091. doi:10.4172/1948-5956.1000397

Copyright: (c 2016 Stramare R, et al. This is an open-access article distributed under the terms of the Creative Commons Attribution License, which permits unrestricted use, distribution, and reproduction in any medium, provided the original author and source are credited. 


\begin{tabular}{|l|l|}
\hline Risk factor & Notes \\
\hline lonizing radiation & Higher risk after a fractionated radiation exposure >10Gy \\
\hline $\begin{array}{l}\text { Virus (EBV, HHV-8, } \\
\text { HIV) }\end{array}$ & $\begin{array}{l}\text { EBV seems implicated in the development of LMS in } \\
\text { HIV-infected and transplant patients }\end{array}$ \\
\hline Chemicals & $\begin{array}{l}\text { Dioxin, chlorophenols } \\
\text { Hi-Fraumeni syndrome, retinoblastoma, Werner's } \\
\text { Hereditary syndromes } \\
\text { syndrome, Rothmund-Thompson syndrome, NF1, } \\
\text { enchondromatosis }\end{array}$ \\
\hline Disease & $\begin{array}{l}\text { Paget's disease (1\% will develop osteosarcoma); } \\
\text { Diamond Blackfan anemia (osteosarcoma) }\end{array}$ \\
\hline Hormones & Female hormone-related factors \\
\hline
\end{tabular}

Table 1: Risk factors associated with STS.

\section{Histology}

Nowadays the histopathologic diagnosis is the gold standard and it provides information about both the grade and the classification of cancer [29]. Usually biopsy is performed at the end of the pre-operative staging and as it must provide a large tissue sample, performing a large core needle biopsy (Tru-cut) [30]. LMS has the phenotypic features of smooth-muscle differentiation and its typical histologic pattern is intersecting, sharply marginated fascicles of proliferating spindle cells with abundant eosinophilic cytoplasmic and elongated (cigar-shaped) nuclei [31,32]; the tumor can often include areas of hemorrhage and necrosis. The advent of new diagnostic tools, such as immunohistochemistry and molecular genetics/molecular cytogenetic, has improved and validated the morphology-based classification scheme [29]. In particular well-differentiated LMSs are usually positive with muscle markers such as actin and desmin, diffusely positive with calponin, h-caldesmon, and negative with S100, c-kit and CD34 so that many tumors that would have formerly been called high-grade spindlecell sarcoma can now be classified as LMS [32-37]. Nonetheless, none of these markers are absolutely specific for smooth muscle differentiation [33]. In contrast to GISTs which are positive for c-kit protein in $>90 \%$ of cases in immunohistochemistry analysis, LMS rarely expresses c-kit and even then, only at low levels $[33,38,39]$.

\section{Diagnostic Imaging}

Multiplanar imaging permits a precise assessment of both size and extent of the tumor prior to biopsy.

Typically, once a lesion showing sarcomatous features has been discovered, diagnosis and staging studies are performed simultaneously. CT is the primary imaging modality for the evaluation of abdominopelvic sarcomas (Figure 1), demonstrating which compartments of the retroperitoneum and mesentery are involved and which vessels and organs are encased or displaced. Moreover, CT provides important information about the staging [29]. To rule out pulmonary and hepatic metastases a dynamic contrast-enhanced CT scan of the thorax, abdomen and pelvis with an arterial phase and a hepatic portal venous phase is usually performed.

CT imaging may show a large, heterogeneous and non-specific mass (average $11 \mathrm{~cm}$ ) [40], with central areas of lower density due to hemorrhage, necrosis or cystic changes; the same features can be seen in liver and lung metastases. In pre-contrast phase high attenuation areas can seldom be seen in cases of recent intra-tumoral hemorrhage [41].

Peripheral moderate contrast enhancement can be observed both in large primary and metastatic tumors because central necrotic portions' lack of an adequate vascularization; smaller tumors can instead be homogeneous [42]. Calcifications are uncommon but

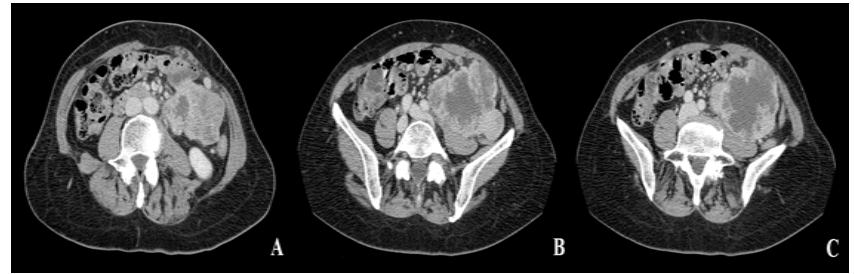

Figure 1: 55-year-old woman with abdominal discomfort. A-B-C. CECT images show a bulky retroperitoneal mass that shows heterogeneous contrastenhancement. The pathological examination revealed it was a LMS.

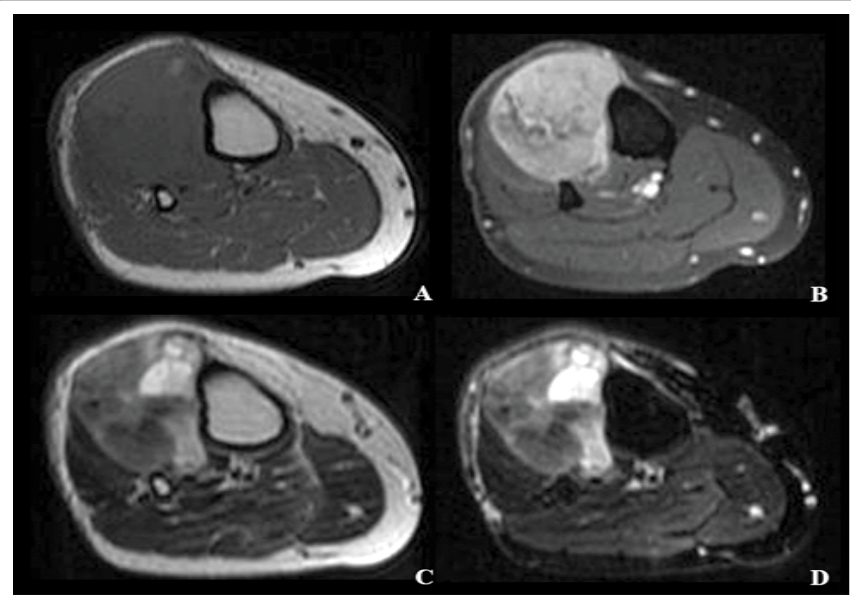

Figure 2: 42-year-old man complaining of a slow-growing tumefaction on his right leg. A-B. T1w-TSE (A) and fatsat T1w-TSE images (B): the lesion appears heterogeneously isointense to skeletal muscle, and it shows strong enhancement after contrast agent administration. (C). On both T2w-TSE and (D) STIR sequences there are high SI areas inside the mass due to necrotic components.

have been reported $[43,44]$; radiographs may show a soft-tissue mass with detectable mineralization in $12-17 \%$ of cases [5,37]. Magnetic resonance imaging (MRI) is the gold standard imaging modality in musculoskeletal tumors evaluation because of its superior soft-tissue contrast, better definition of tumor boundaries (Figure 2) [29] and its multiplanar capabilities. MRI allows a better assessment of the site of origin of a mass, in particular within the pelvis and its involvement with local structures $[29,45]$. Sequences that are performed in our standard protocol for the assessment of soft tissue lesions are: Turbo Spin Echo T1-weighted, Turbo Spin Echo T2-weighted, STIR (Short Tau Inversion Recovery), dynamic contrast enhanced before and after gadolinium injection VIBE (Volumetric Interpolated Breath-hold Examination) and DWI (Diffusion Weighted Imaging).

Lesions are typically isointense to muscle on T1-weighted images and variably hyperintense relative to muscle on T2-weighted images, with prominent peripheral contrast-enhancement (Figure 3) [37,46].

Large deep lesions can be heterogeneous with areas of liquefaction seen as low-signal intensity regions in T1-weighted imagines and highsignal in T2-weighted images [29]; on the other hand, superficial lesions which are usually smaller, tend to be more homogeneous. Dynamic contrast-enhanced MRI is often used to try to distinguish benign from malignant lesions: according to $\mathrm{Ma}$ and co-workers [47] rim-to-center decreasing enhancement ratio is an additional parameter of malignancy for the MR imaging differentiation of indeterminate musculoskeletal masses (Figure 4). However, MRI findings are nonspecific and reflect a spindle-shaped non-fatty mass with a long T1 and a long T2 


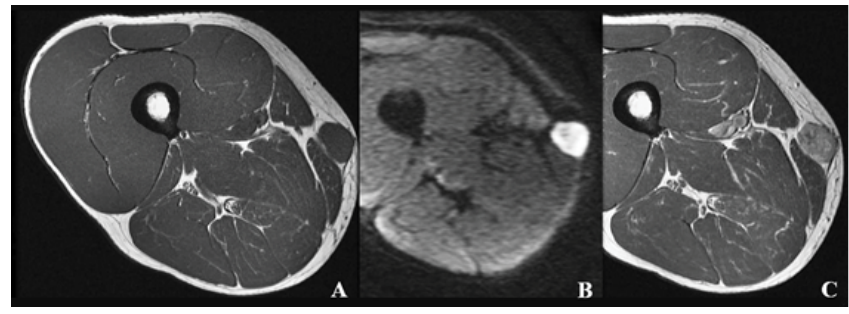

Figure 3: 39-year-old man with a palpable nodule in the right thigh. (A): T1w-TSE image shows a subcutaneous nodule with isointense to skeletal muscle. (B): It is hyperintense on STIR sequence. (C): It reveals moderate but widespread contrast-enhancement after Gd-based contrast agent administration, suggestive of solid and malignant nature.

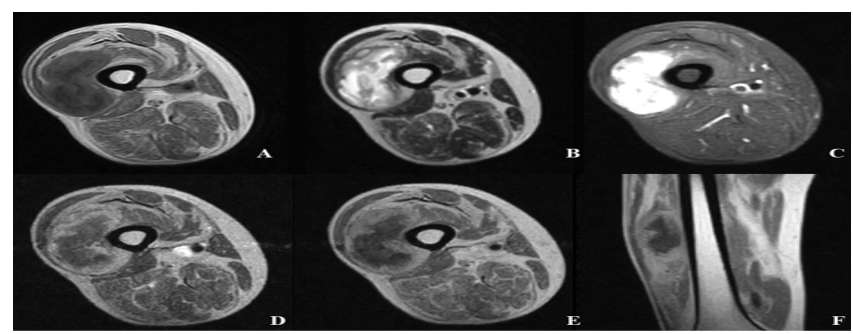

Figure 4: 65-year-old man with a LMS of the thigh. (A): On T1w-TSE image there is a mass in the lateral compartment of the right thigh. The mass appears heterogeneous with a peripheral zone of intermediate $\mathrm{SI}$, and a central zone of lower SI. This central area results brightly hyperintense on T2w-TSE (B) and STIR (C) images, suggesting colliquation. (D-E-F): Both the axial and coronal T1w-TSE images obtained after C.A. administration confirm the presence of a heterogeneous mass with solid and viable tissue in periphery and a necrotic core. The lesion reaches the femoral shaft, but neither the cortex nor the bone marrow seem infiltrated.

relaxation time. Therefore, the main MR imaging features that should raise suspicion of LMS are a mass isointense to skeletal muscle on T1weighted images and variably hyperintense relative to muscle on $\mathrm{T} 2$ weighted images, with contrast-enhancement following gadolinium administration especially in a peripheral rim-like fashion [37,48-52]. There is no clear evidence about the role of diffusion-weighted imaging in the diagnostic pathway of these tumors; according to Sato and coworkers [53], it seems feasible to differentiate leiomyoma from LMS by combining signal intensity on diffusion-weighted imaging and apparent diffusion coefficient (ADC).

\section{Locations}

Histologically, soft tissue leiomyosarcomas that arise in different anatomic locations are similar. However, based on the location of the tumor, prognosis and possible treatments can differ. Retroperitoneal LMSs develop insidiously and are generally reported as big masses [54]; one of the major concerns in their radiologic characterization regards the site of origin, in particular whether they are primary from the retroperitoneum or from a retroperitoneal organ [6]. There are few CT signs that may be potentially helpful in differentiating LMSs arising from retroperitoneal space and tumors that develop from retroperitoneal organs: embedded sign, beak sign, "phantom organ" sign and prominent feeding artery sign [6]. A "positive embedded organ" sign identifies a mass arising from a "plastic organ" (i.e. the bowel or veins) [55]. If the organ in question is embedded in the periphery of a larger mass, the mass is likely to arise from that organ (positive embedded organ sign), while if the organ is compressed, the mass doesn't arise from that organ (Figures 5 and 6).

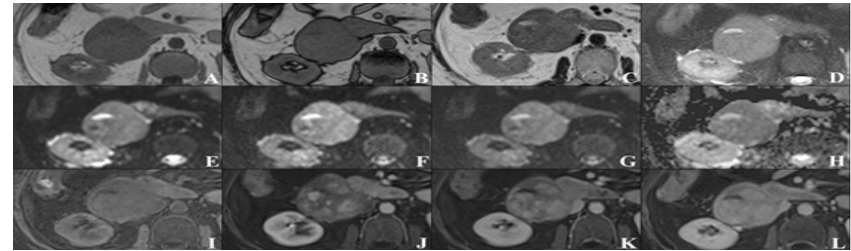

Figure 5: 61-year-old woman with a retroperitoneal LMS who presented with weakness, abdominal discomfort and leg heaviness. (A-B): T1w-GRE in/out of phase: a bulky retroperitoneal mass between the right kidney and inferior vena cava; it shows a pretty homogeneous signal intensity except for a crescentshaped hypointense area. There is no drop of signal (chemical shift effect) in the out-of-phase sequence suggesting the absence of both fat and water protons in the same voxels. (C-D): It shows an intermediate SI on T2w-TSE sequence that increases on STIR image; the crescent-shaped lacuna reveals high SI suggesting its fluid nature. (E-F-G-H): Dwl images with b values of 50$400-1000 \mathrm{~s} / \mathrm{mm}^{2}$ show high signal intensity also on the high $b$ value image with a low $A D C$ value, in the corresponding ADC map $(H)$, consistent with restricted diffusion. On the contrary the crescent-shaped lacuna shows a progressive decrease in $\mathrm{SI}$ going through the $b$ values and a high ADC value, suggesting no restricted diffusion. (I-J-K-L) Precontrast and postcontrast fatsat-T1w-VIBE images: the mass shows heterogeneous contrast-enhancement with inner nodules; moreover, the lesion compresses the inferior vena cava lumen which is still patent suggesting its retroperitoneal origin (negative embedded organ sign)

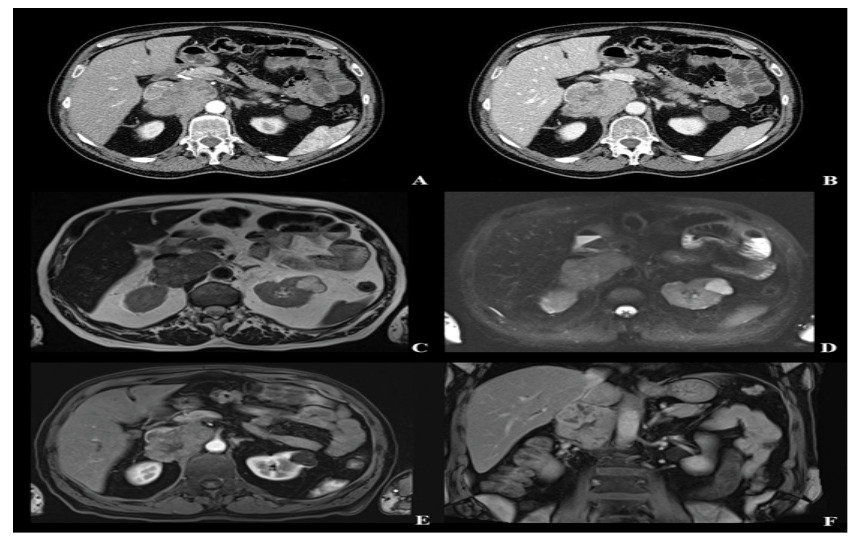

Figure 6: 53-year-old man with a retroperitoneal mass causing lowe extremities edema at presentation. (A-B): CT images obtained after IV contrast agent administration in both (A) arterial and (B) portal phases reveal a large retroperitoneal mass adjacent to aorta, in the expected location of IVC. There are partial compression of the IVC lumen, intraluminal tumoral growth along the adventitia of the vessel and extrinsic compression. (C-D-E-F): The neoplasm shows heterogeneous SI on T1w-TSE (C) and high SI on SPAIR T2w-TSE (D) sequences; after IV administration of contrast medium, the tumor reveals increasing contrast-enhancement on arterial $(E)$ and venous $(F)$ phases, with a crescent-shaped residual patent lumen of IVC.

When the edges between the mass and a specific organ are sharp the beak sign is positive. Thus indicating that the origin of the mass comes from this specific organ. Vice-versa, in case of compression, the edges are dull and the beak sign is negative. The phantom organ sign is positive when the mass, originated from a small organ, makes it undetectable. Lastly, the "prominent feeding artery sign" is identified when the caliber of an arterial vessel that supplies a specific organ becomes larger than usual. Retroperitoneal LMSs can often involve inferior vena cava (IVC) and others large venous vessels following three main growth patterns: extra-luminal (62\%), both extra- and intra-luminal (33\%) and intraluminal (5\%). The ones with an exclusive intra-luminal growth pattern primarily arise from the ICV and can be considered of vascular origin. Thus, when primary IVC tumors have even an extravascular extension as well, it can be difficult to distinguish the initial site of origin [55-59]. 
CE-CT and CE-MRI, can be useful in identifying the extent of vessel involvement and the presence of intraluminal tumors or neoplastic thrombi; another main distinction to be made concerns the differentiation between intravascular tumors and non-neoplastic thrombi. An MRI can provide important clues to distinguish these two entities (i.e. enlargement of the IVC, the relative high intensity on T2w sequences, and presence or absence of contrast-enhancement; Figure 5) [59]. Moreover, a tumor expands the vessel to a diameter several times its original one, while thrombus never expands the diameter to more than twice its original one $[50,60]$.

In literature, the limbs are reported to be the second-most common site of soft tissue-LMS, particularly buttocks and thighs; they can arise from vascular structures (mainly veins) or hair follicles (erector pili muscle) [4]. Extremity LMSs are usually present as painless slowgrowing lesions, which may seem clinically benign.

LMS of the lower limbs, arising from the deep venous system initially present with signs of deep venous thrombosis and exhibit similar prognostic patterns as LMS arising from inferior vena cava and other venous tributaries [61].

Imaging is non-specific: ultrasound reveals a hypoechoic solid mass, which may be ill- or well-defined with marked internal vascularization [62-64]. As for retroperitoneal LMS, the MRI is the best imaging choice for the evaluation of extremity tumors. Large and deep lesions are usually heterogeneous with central areas of necrosis. Superficial ones tend to be smaller and more homogeneous. On MRI images, peripheral LMSs are iso- or hyper-intense to muscle on T1weighted images and hyperintense on T2-weighted images with mild to intense contrast-enhancement of the viable areas [52]. Calcifications are uncommon (10-20\%) on radiographs and CT images [65]. Even if they are not properly classified as soft tissue lesions, uterine LMS account for about $40 \%$ of leiomyosarcomas among women; moreover, they represent approximately one-third of uterine sarcomas and $1 \%$ of all uterine malignancies. Sarcomatous transformation of a preexisting leiomyoma occurs but it is uncommon; most of the time LMSs arise independently [66]. Irregular margins of a uterine leiomyoma through MRI imaging suggest a sarcomatous transformation, but the specificity of this finding has not been established. The diagnosis of leiomyosarcomas is established by a pathologist after surgery [67].

Cutaneous LMSs are rare, slow-growing tumors that occur in middle-aged and elderly patients and account for $2-6 \%$ of all superficial sarcomas [52]. Superficial cutaneous LMSs arise from the arrectores pilorum muscles and appear as small firm nodules $(<2 \mathrm{~cm})$; they have a good prognosis with a low metastatic risk $(10 \%)$ though local lymph nodes may be positive and have frequent local recurrence $[9,52,65]$. Subcutaneous forms arising from small blood vessel walls are usually larger, with frequent local recurrences and metastatic disease (30-50\% of cases) [65]. MRI features of superficial LMSs are similar to the ones described for extremity located LMSs. Primary leiomyosarcoma of the bone is extremely rare and should be distinguished from a metastasis of an extra osseous primary site, often the uterus. It appears purely osteolytic with aggressive features but differently from other osteolytic lesions it can also have fibrous or muscle components. The tumor is primary intramedullary in origin but can involve the surrounding soft tissue, typically with a subtle periosteal reaction [28].

\section{Differential Diagnosis}

The main differential diagnosis of Soft tissue LMS concerns gastrointestinal stromal tumors (GISTs), Primitive Neuroendocrine Tumors (PNETs), lymphomas and others soft tissue tumors
[31,33,35,36]. Intra-abdominal and pelvic GISTs can show similar imaging features as LMSs but they are most frequently found in the stomach and small bowel. The definitive diagnosis is however provided by an immunohistochemical characterization since they show c-kit expression. PNETs can have intravascular origin such as intravascular LMSs, and they have a non-specific imaging appearance. Lastly, large abdominal or pelvic, necrotic lymphomas can mimic LMSs. (Table 2).

\section{Management of LMSs}

Patients with STS should be referred to hospitals with extensive experience in managing sarcomas using multidisciplinary care approach (Figure 7). Surgery is the mainstay of therapy in LMS and only wide or radical resections are defined as adequate. The surgical approach and execution should be planned on the basis of imaging findings. If the lesion is close to the structures such as the vascular-nervous fascia or bone, the fascia covering these structures should be removed (muscle fascia, vascular adventitia, epineurium or periosteum). If these barriers are infiltrated, the underlying structures should be resected en bloc with the tumor.

For LMS involving the inferior vena cava (IVC), and other vascular structures, extensive, en bloc resection of the tumor and the involved vessel is of paramount importance in order to obtain R0 resection margins. As such extensive resection often involves a large amount of collaterals, caval reconstruction should always be considered in order to avoid invalidating lower limbs edema and ameliorate the quality of life [68]. Post-resection margin status plays a significant role in determining prognosis. Surgery with wide negative margins (R0 resection) is the only potentially curative treatment assuring local control of LMSs [67-71]. The administration of other treatment modalities, such as chemotherapy and radiation therapy improves the control of the local disease and the outcome, especially with high-grade STS $[4,72,73]$. Combination of surgery and chemotherapy seems the most effective treatment in many settings. Though only $50 \%$ of patients respond to chemotherapy with less than $10 \%$ long-term survival, many promising

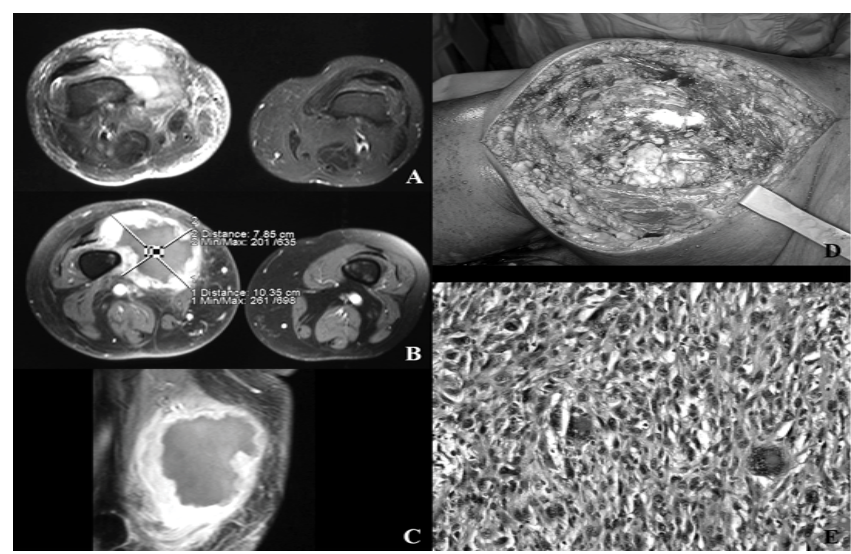

Figure 7: 60-year-old woman with LMS of the thigh who underwent hyperthermic limb perfusion (HLP) with TNFa and L-PAM two months before. (A): T2w-TSE with fat-suppression technique: the lesion shows heterogeneous signal intensity with a hyperintense central area of colliquation. (B-C): T1wTSE with fat-suppression technique after IV administration of Gd-based contrast agent: this sequence reveals peripheral contrast-enhanced solid tissue with an avascular hypointense (necrotic) core. (D): Incisional biopsy: the gross appearance confirms the heterogeneity of this lesion with a peripheral solid component and a central polilobulated necrotic core. (E): High-power view of LMS, with hematoxylin/eosin staining showing bundles of cells with polymorphic-shaped nuclei; the histology confirmed $90 \%$ of necrosis and microscopically infiltrated margins. 
Citation: Stramare R, Orsatti G, Attar S, Rastrelli M, Brunello A (2016) Imaging Features, Differential Diagnosis and Management of Leiomyosarcomas: Case Series and Review of the Literature. J Cancer Sci Ther 8: 084-091. doi:10.4172/1948-5956.1000397

\begin{tabular}{|c|c|c|c|c|}
\hline Tumor & Sex & Decade & Anatomical sites & Imaging features \\
\hline LMS & $M>F$ & $5-6$ th & $\begin{array}{l}\text { Extremities (thigh); } \\
\text { Retroperitoneum }\end{array}$ & $\begin{array}{l}\text { - Non-specific mass; } \\
\text { - Large lesions with hemorrhage, necrosis, and } \\
\text { cystic changes }\end{array}$ \\
\hline Leyomioma & $M=F$ & $3 r d$ & $\begin{array}{l}\text { Subcutaneous or deep-seated; } \\
\text { extensor surfaces of extremities }\end{array}$ & $\begin{array}{l}\text { - Mimic LMS; } \\
\text { - highly vascular lesions with aggressive behavior; } \\
\text { - mulberry -like calcifications; }\end{array}$ \\
\hline Liposarcoma & $M \geq F$ & 5-6th & Abdomen, extremities & $\begin{array}{l}\text { - Heterogeneous, multi-lobulated, typically well- } \\
\text { defined mass of variable US appearance; } \\
\text { - Heterogeneous attenuation with thick septa. } \\
\text { - Adipose areas; } \\
\text { - Non-adipose areas: low T1w, high T2w; } \\
\text { - variable CE }\end{array}$ \\
\hline GIST & $M>F$ & $6-7$ th & $\begin{array}{l}\text { Gastrointestinal tract, mesentery } \\
\text { and peritoneum }\end{array}$ & $\begin{array}{l}\text { - Exophytic growth pattern } \\
\text { - Dominant masses (> outside the organ of origin) } \\
\text { - Heterogeneity: may contain areas of hemorrhage, } \\
\text { necrosis, or cyst formation } \\
\text { - solid components show low SI on T1w, } \\
\text { intermediate-to-high SI on T2w, and CE }\end{array}$ \\
\hline $\begin{array}{l}\text { Dermatofibro-sarcoma } \\
\text { protuberans }\end{array}$ & $M>F$ & 3rd-5th & $\begin{array}{l}\text { Trunk }(50 \%) \\
\text { extremities }\end{array}$ & $\begin{array}{l}\text { - Linear subcutaneous protuberant mass with skin } \\
\text { involvement (best appreciate with a long TR } \\
\text { - Nequence) } \\
\text { - Non-specific features } \\
\text { - Heterogeneity (hemorrhage, necrosis) } \\
\text { Moderate CE }\end{array}$ \\
\hline $\begin{array}{l}\text { Undifferentiated Plemorphic } \\
\text { Sarcoma (UPS) }\end{array}$ & $M \gg>F$ & 5 th & Lower extremities & $\begin{array}{l}\text { - Large heterogeneous mass; } \\
\text { - Intermediate-to-low echogenicity; } \\
\text { - Areas of lower attenuation and heterogeneous CE } \\
\text { - Intermediate Si on T1w; } \\
\text { - High SI on T2w } \\
\text { - CE of solid areas }\end{array}$ \\
\hline Angiosarcoma & $M>F$ & $\begin{array}{l}\text { All decades (peak } \\
\text { incidence in } 7 \text { th) }\end{array}$ & $\begin{array}{l}\text { Cutaneous form (Scalp; Face) } \\
\text { Extremities; } \\
\text { Trunk; } \\
\text { Retroperitoneum }\end{array}$ & $\begin{array}{l}\text { - Non-specific; } \\
\text { - Lymphedema }\end{array}$ \\
\hline Agio-leiomyoma & $M<F$ & 4-6th & $\begin{array}{l}\text { Subcutaneous tissue of extremities } \\
(>\text { foot })\end{array}$ & $\begin{array}{l}\text { - }<2 \mathrm{~cm} \text { well-defined solitary nodule; } \\
\text { - possible areas of myxoid change, calcifications and } \\
\text { fat areas } \\
\text { - Similar to skeletal muscle on T1w } \\
\text { - High or mixed signal on T2w } \\
\text { - Marked CE }\end{array}$ \\
\hline
\end{tabular}

Table 2: Leiomyosarcoma: main differential diagnosis among other STT.

new agents are under active investigation or are being explored in pre-clinical models [74,39]. Apart from the standard chemotherapy regimens based on anthracyclines, LMS have been found to respond to other drugs such as trabectedin, dacarbazine, gemcitabine and docetaxel in the advanced setting $[75,76]$.

As for patients with localized disease, though there is no consensus on the current role of adjuvant chemotherapy, generally this is taken into account for large, deep-seated, high grade STS [77]. The standard regimen to be used in the adjuvant setting is based on either doxorubicin or epirubicin and ifosfamide [78], yet in light of the specific sensitivity of some histological subtypes to cytoxic drugs other than doxorubicin and ifosfamide, a trial led by Italian Sarcoma Group is ongoing also in our Institute comparing standard chemotherapy versus histologydriven chemotherapy.

For the specific histological subtype of LMS, the trial randomizes patients between the standard arm which comprises three courses of (neo) adjuvant chemotherapy with epirubicin and ifosfamide ì and the experimental arm, which comprises three courses of dacarbazine and gemcitabine. In the pre-operative setting, after the chemotherapy has been concluded, a further radiological evaluation is carried out for response assessment [30]

Furthermore, patients who are candidates for conservative surgery, including those in which re-excision is planned, should be considered for radiation therapy.
Pre-operative radiation therapy is recommended in locally advanced sarcomas, in order to facilitate the excision and usually starts after the first cycle of neoadjuvant chemotherapy. Adjuvant radiotherapy is administered in high-grade, deep tumors, tumors larger than $5 \mathrm{~cm}$, in case of microscopic marginal resection (tumor close to bone, nerve or vessels) and incomplete surgical excision [30]. Radiotherapy may also be used in the palliative setting of metastatic disease. A close followup, including radiological evaluation must be performed, particularly for high-risk LMSs as these tumors have a high incidence of local recurrence.

\section{Prognosis}

The prognosis of LMS is poor with an overall survival rate of $35 \%$. The most important prognostic factors are tumor size and anatomic site. Prognosis is worse for tumor dimensions greater than $5 \mathrm{~cm}$ and for retroperitoneal tumors [29] that are fatal in the majority of cases with a mortality rate of $85-90 \%$ within $2-5$ years [5].

Other important prognostic factors that, according to the American Joint Committee on Cancer (AJCC), decrease the survival rate are depth, mitotic rate of $>20$ per 10 high-power fields (HPF), tumor necrosis of $>50 \%$ and a high-stage [79]. Surgical margins seem to be the most important predictors of local recurrence with a very low-risk of recurrence when they are microscopically negative [80]. Despite achieving local control through surgery and radiation therapy, up to $30 \%$ of patients will experience a recurrence at distant sites [31]. 
Citation: Stramare R, Orsatti G, Attar S, Rastrelli M, Brunello A (2016) Imaging Features, Differential Diagnosis and Management of Leiomyosarcomas: Case Series and Review of the Literature. J Cancer Sci Ther 8: 084-091. doi:10.4172/1948-5956.1000397

Metastasis from LMS tend to have a hematogenous spread and the most frequently involved organs are the liver and the lung (Figures 8 and 9), occurring in $53 \%$ and $47 \%$ of patients respectively, followed by other sites (Table 3) [29]. LMSs can also spread within the peritoneum when the tumor grows toward the subserosa from its site of origin, develop a central excavation and perforate into the peritoneal cavity. In these cases, the imaging shows peritoneal leiomyosarcomatosis as multiple, discrete peritoneal or mesenteric masses, with central lowattenuation areas on CT [81]. Retroperitoneal tumors have the highest rate of metastasis $(40-50 \%)$; metastasis from subcutaneous tumors

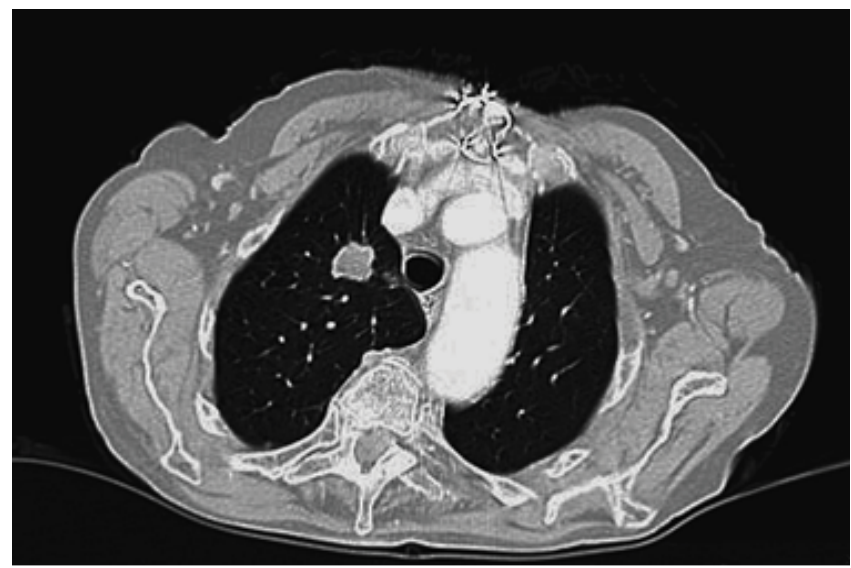

Figure 8: 45-year-old man with LMS of the lower extremities. The chest CECT reveal a solid polilobulated pulmonary nodule with speculated margins in the right upper lobe, showing pheripherical enhancement.

\begin{tabular}{|c|c|}
\hline Site & Frequency \\
\hline Liver & $53 \%$ \\
\hline Lung & $47 \%$ \\
\hline Cutaneous tissue & $23 \%$ \\
\hline Bone & $18 \%$ \\
\hline Lymphnodes & $18 \%$ \\
\hline Gastrointestinal tract & $18 \%$ \\
\hline
\end{tabular}

Table 3: Metastatic sites and their prevalence.

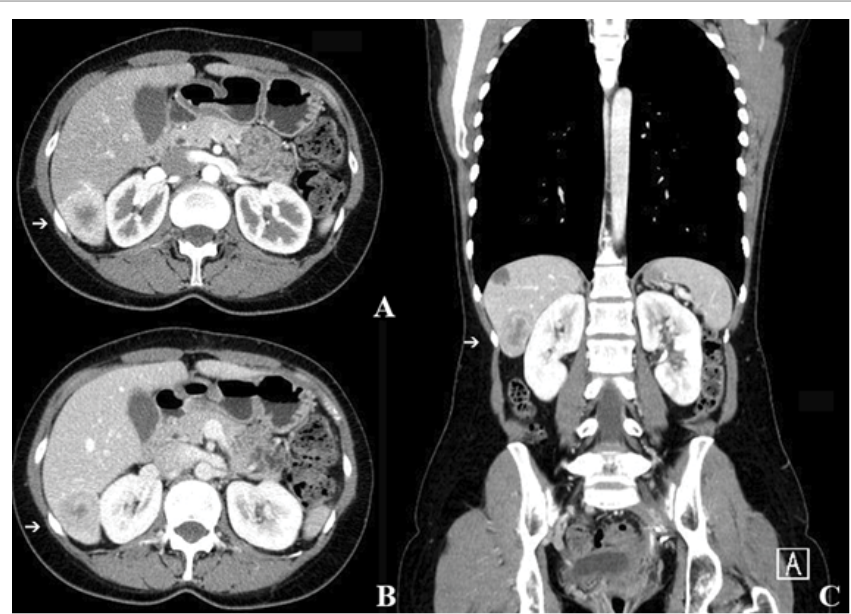

Figure 9: 45-year-old man with LMS of the lower extremities. (A-B-C): On contrast-enhanced CT performed for staging purpose there is a metastatic liver lesion in the $\mathrm{VI}$ hepatic segment (white arrow). It shows heterogeneous targetlike $C E$, with a hypodense core and a peripheral hyper-enhancing rim on both arterial $(A)$ and portal phases $(B, C)$. occur in about $30 \%$ of patients; and hematogenous dissemination from superficial epidermal lesions is extremely rare.

\section{Conclusion}

LMSs are relatively frequent among STSs and are considered aggressive neoplasms with a poor outcome. Retroperitoneum and extremities are the most common localizations. Radiologic features are non-specific and the diagnosis is mainly achieved through histopathological examination. In CT imaging suspicion of LMS diagnosis should be considered in the event of a large and heterogeneous mass. MR imaging is the gold standard in soft tissue characterization, tumor site of origin detection and local staging; LMS appears as an isointense lesion on T1w images and intermediate to hyper-intense mass on T2w images; both CE-CT and CE-MRI show an intense peripheral enhancement (target sign). Much remains to be learned about the mechanisms underlying the development of the aggressive behavior of this tumor. New targeted therapies may arise from the knowledge of the underlying molecular pathways involved in the pathogenesis of LMS.

\section{References}

1. Fletcher CDM, Unni KK, Mertens F (2002) World Health Organization Classification of tumors: pathology and genetics of tumors of soft tissue and bone. IARC Press, Lyon.

2. Stramare R, Beltrame V, Gazzola M, Gerardi M, Scattolin G, et al. (2013) Imaging of soft-tissue tumors. J Magn Reson Imaging 37: 791-804.

3. Bathan AJ, Constantinidou A, Pollack SM, Jones RL (2013) Diagnosis prognosis, and management of leiomyosarcoma: recognition of anatomic variants. Curr Opin Oncol 25: 384-389.

4. Picci M, Manfrini M, Fabbri N, Gambarotti M, Vanel D (2014) Atlas of Musculoskeletal Tumors and Tumorlike Lesions, The Rizzoli Case Archive. Springer.

5. Davies CE, Davies AM, Kindblom LG, James SL (2010) Soft tissue tumors with muscle differentiation. Semin Musculoskelet Radiol 14: 245-256.

6. Nishino M, Hayakawa K, Minami M, Yamamoto A, Ueda H, et al. (2003) Primary retroperitoneal neoplasms: CT and MR imaging findings with anatomic and pathologic diagnostic clues. Radiographics 23: 45-57.

7. Ng VY, Scharschmidt TJ, Mayerson JL, Fisher JL (2013) Incidence and survival in sarcoma in the United States: a focus on musculoskeletal lesions. Anticancer Res 33: 2597-2604.

8. Ren B, Yu YP, Jing L, Liu L, Michalopoulos GK, et al. (2003) Gene expression analysis of human soft tissue leiomyosarcomas. Hum Pathol 34: 549-558.

9. Svarvar C, Böhling T, Berlin O, Gustafson P, Follerås G, et al. (2007) Clinical course of nonvisceral soft tissue leiomyosarcoma in 225 patients from the Scandinavian Sarcoma Group. Cancer 109: 282-291.

10. Paal E, Miettinen M (2001) Retroperitoneal leiomyomas: a clinicopathologic and immunohistochemical study of 56 cases with a comparison to retroperitoneal leiomyosarcomas. Am J Surg Pathol 25: 1355-1363.

11. Toro JR, Travis LB, Wu HJ, Zhu K, Fletcher CD, et al. (2006) Incidence patterns of soft tissue sarcomas, regardless of primary site, in the surveillance, epidemiology and end results program, 1978-2001: an analysis of 26,758 cases. Int J Cancer 119: 2922-2930

12. Ege B, Leventoglu S (2013) Primary leiomyosarcoma of the thyroid. J Korean Surg Soc 85: 43-46.

13. Tanboon J, Keskool P (2013) Leiomyosarcoma: a rare tumor of the thyroid. Endocr Pathol 24: 136-143.

14. Amal B, El Fatemi H, Souaf I, Moumna K, Affaf A (2013) A rare primary tumor of the thyroid gland: report a new case of leiomyosarcoma and literature review. Diagn Pathol 8: 36.

15. Mouaqit O, Belkacem Z, Ifrine L, Mohsine R, Belkouchi A (2014) A rare tumo of the thyroid gland: report on one case of leiomyosarcoma and review of literature. Updates Surg 66: 165-167.

16. Park EY, Seo HI, Yun SP, Kim S, Kim JY, et al. (2012) Primary leiomyosarcoma of gallbladder. J Korean Surg Soc 83: 403-407. 
Citation: Stramare R, Orsatti G, Attar S, Rastrelli M, Brunello A (2016) Imaging Features, Differential Diagnosis and Management of Leiomyosarcomas: Case Series and Review of the Literature. J Cancer Sci Ther 8: 084-091. doi:10.4172/1948-5956.1000397

17. Savlania A, Behera A, Vaiphei K, Singh H, Dhiman RK, et al. (2012) Primary leiomyosarcoma of gallbladder: a rare diagnosis. Case Rep Gastrointest Med 2012: 287012.

18. Wachter DL, Büttner MJ, Grimm K, Hartmann A, Agaimy A (2010) Leiomyoma of the gallbladder: a case report with review of the literature and discussion of the differential diagnosis. J Clin Pathol 63: 177-179.

19. Croce A, Moretti A, Laus M, Crescenzi D (2012) Leiomyosarcoma of the base of the tongue and free edge of the epiglottis: a case report. J Med Case Rep 6: 400 .

20. Ahn JH, Mirza T, Ameerally P (2012) Leiomyosarcoma of the tongue with multiple metastases: a case report and review of literature. J Oral Maxillofac Surg 70: 1745-1750.

21. Tsai PS, Yeh TC, Shih SL (2013) Primary hepatic leiomyosarcoma in a 5-monthold female infant. Acta Radiol Short Rep 2: 2047981613498722.

22. Chelimilla H, Badipatla K, Ihimoyan A, Niazi M (2013) A rare occurrence of primary hepatic leiomyosarcoma associated with epstein barr virus infection in an AIDS patient. Case Rep Gastrointest Med 2013: 691862.

23. Lee MC, Hsu CP, Hsia JY (2008) Surgical treatment of endobronchial leiomyosarcoma with right main bronchus total obstruction: a case report. Ann Thorac Cardiovasc Surg 14: 105-108.

24. Martínez-Cornelio A, Ramos-Salgado F, Hernández-Ramírez D, GarcíaÁlvarez KG, Alvarado-Cabrero I, et al. (2011) Leiomyosarcoma of the kidney: case report. Cir Cir 79: 260-2, 282-5.

25. Miller JS, Zhou M, Brimo F, Guo CC, Epstein JI (2010) Primary leiomyosarcoma of the kidney: a clinicopathologic study of 27 cases. Am J Surg Pathol 34: 238-242.

26. Xu J, Zhang T, Wang T, You L, Zhao Y (2013) Clinical characteristics and prognosis of primary leiomyosarcoma of the pancreas: a systematic review. World J Surg Oncol 11: 290

27. Ogura T, Masuda D, Kurisu Y, Miyamoto Y, Hayashi M, et al. (2013) Multiple metastatic leiomyosarcoma of the pancreas: a first case report and review of the literature. Intern Med 52: 561-566.

28. Italiano A, Lagarde P, Brulard C, Terrier P, Laë M, et al. (2013) Genetic profiling identifies two classes of soft-tissue leiomyosarcomas with distinct clinical characteristics. Clin Cancer Res 19: 1190-1196.

29. O'Sullivan PJ, Harris AC, Munk PL (2008) Radiological imaging features of nonuterine leiomyosarcoma. $\mathrm{Br} \mathrm{J}$ Radiol 81: 73-81.

30. Italian Sarcoma Group (2010) Localized High-Risk Soft Tissue Sarcomas of the extremities and trunk wall in adults: an integrating approach comprising standard vs histotype tailored neoadjuvant chemotherapy (ISG-STS 10-01). National Institutes of Health, USA.

31. Mastrangelo G, Coindre JM, Ducimetière F, Dei Tos AP, Fadda E, et al. (2012) Incidence of soft tissue sarcoma and beyond: a population-based prospective study in 3 European regions. Cancer 118: 5339-5348.

32. Ragazzini P, Gamberi G, Pazzaglia L, Serra M, Magagnoli G, et al. (2004) Amplification of CDK, MDM, SAS and GLI genes in leiomyosarcoma, alveolar and embryonal rhabdomyosarcoma. Histol Histopathol 19: 401-411

33. Yang J, Du X, Chen K, Ylipää A, Lazar AJ, et al. (2009) Genetic aberrations in soft tissue leiomyosarcoma. Cancer Lett 275: 1-8.

34. Arbiser ZK, Folpe AL, Weiss SW (2001) Consultative (expert) second opinions in soft tissue pathology. Analysis of problem-prone diagnostic situations. Am J Clin Pathol 116: 473-476.

35. Harris M, Hartley AL, Blair V, Birch JM, Banerjee SS, et al. (1991) Sarcomas in north west England: I. Histopathological peer review. Br J Cancer 64: 315-320.

36. Fletcher CD, Berman JJ, Corless C, Gorstein F, Lasota J, et al. (2002) Diagnosis of gastrointestinal stromal tumors: A consensus approach. Hum Pathol 33: 459-465.

37. Bush CH, Reith JD, Spanier SS (2003) Mineralization in musculoskeletal leiomyosarcoma: radiologic-pathologic correlation. AJR Am J Roentgenol 180: 109-113

38. Meza-Zepeda LA, Kresse SH, Barragan-Polania AH, Bjerkehagen B, Ohnstad $\mathrm{HO}$, et al. (2006) Array comparative genomic hybridization reveals distinc DNA copy number differences between gastrointestinal stromal tumors and leiomyosarcomas. Cancer Res 66: 8984-8993
39. Trent JC, Lazar AJ, Zhang W (2007) Molecular approaches to resolve diagnostic dilemmas: the case of gastrointestinal stromal tumor and leiomyosarcoma. Future Oncol 3: 629-637.

40. Lane RH, Stephens DH, Reiman HM (1989) Primary retroperitoneal neoplasms: CT findings in 90 cases with clinical and pathologic correlation. AJR Am J Roentgenol 152: 83-89.

41. Hartman DS, Hayes WS, Choyke PL, Tibbetts GP (1992) From the archives of the AFIP. Leiomyosarcoma of the retroperitoneum and inferior vena cava: radiologic-pathologic correlation. Radiographics 12: 1203-1220.

42. Coran A, Di Maggio A, Rastrelli M, Alberioli E, Attar S, et al. (2015) Core needle biopsy of soft tissue tumors, CEUS vs US guided: a pilot study. J Ultrasound 18: $335-342$

43. Rubin BP, Fletcher JA, Fletcher CD (2000) Molecular Insights into the Histogenesis and Pathogenesis of Gastrointestinal Stromal Tumors. Int J Surg Pathol 8: 5-10.

44. Bancroft LW, Peterson JJ, Kransdorf MJ (2005) MR imaging of tumors and tumor-like lesions of the hip. Magn Reson Imaging Clin N Am 13: 757-774.

45. Walker EA, Salesky JS, Fenton ME, Murphey MD (2011) Magnetic resonance imaging of malignant soft tissue neoplasms in the adult. Radiol Clin North Am 49: $1219-1234$

46. Walker EA, Song AJ, Murphey MD (2010) Magnetic resonance imaging of softtissue masses. Semin Roentgenol 45: 277-297.

47. Ma LD, Frassica FJ, McCarthy EF, Bluemke DA, Zerhouni EA (1997) Benign and malignant musculoskeletal masses: MR imaging differentiation with rim-tocenter differential enhancement ratios. Radiology 202: 739-744

48. Park MY, Jee WH, Kim SK, Lee SY, Jung JY (2013) Preliminary experience using dynamic MRI at 3.0 Tesla for evaluation of soft tissue tumors. Korean J Radiol 14: 102-109.

49. Tuncbilek N, Karakas HM, Okten OO (2005) Dynamic contrast enhanced MR in the differential diagnosis of soft tissue tumors. Eur J Radiol 53: 500-505.

50. Seynaeve PC, De Visschere PJL, Mortelmans LL, De Schepper AM (2006) Tumors of muscular origin. In: De Schepper AM, Parizel PM, Vanhoenacker FM (eds) Imaging of soft tissue tumors. Springer, Berlin, Heidelberg

51. Sundaram M, McLeod RA (1990) MR imaging of tumor and tumorlike lesions of bone and soft tissue. AJR Am J Roentgenol 155: 817-824.

52. Kransdorf MJ, Murphey MD (2006) Muscle tumors. In: Kransdorf MJ, Murphey MD (eds) Imaging of soft tissue tumors. (2ndedtn), Lippincott Williams \& Williams, Philadelphia.

53. Sato K, Yuasa N, Fujita M, Fukushima Y (2013) Clinical application of diffusionweighted imaging for preoperative differentiation between uterine leiomyoma and leiomyosarcoma. Am J Obstet Gynecol 210: 368.e1-8

54. Gemici K, Buldu I, Acar T, Alptekin H, Kaynar M, et al. (2015) Management of patients with retroperitoneal tumors and a review of the literature. World J Surg Oncol 13: 143

55. Webb EM, Wang ZJ, Westphalen AC, Nakakura EK, Coakley FV, et al. (2013) Can CT features differentiate between inferior vena cava leiomyosarcomas and primary retroperitoneal masses? AJR Am J Roentgenol 200: 205-209.

56. Huang J, Liu Q, Lu JP, Wang F, Wang L, et al. (2011) Primary intraluminal leiomyosarcoma of the inferior vena cava: value of MRI with contrast-enhanced MR venography in diagnosis and treatment. Abdom Imaging 36: 337-341.

57. Mingoli A, Cavallaro A, Sapienza P, Di Marzo L, Feldhaus RJ, et al. (1996) International registry of inferior vena cava leiomyosarcoma: analysis of a world series on 218 patients. Anticancer Res 16: 3201-3205.

58. Narata M, Okuhata Y, Abe K, Takemoto A, Maebayashi T, et al. (2010) Primary leiomyosarcoma of the inferior vena cava: case report. Abdom Imaging 35 481-484.

59. Hemant D, Krantikumar R, Amita J, Chawla A, Ranjeet N (2001) Primary leiomyosarcoma of inferior vena cava, a rare entity: Imaging features. Australas Radiol 45: 448-451.

60. Sostman HD, Prescott DM, Dewhirst MW, Dodge RK, Thrall DE, et al (1994) MR imaging and spectroscopy for prognostic evaluation in soft-tissue sarcomas. Radiology 190: 269-275.

61. Illuminati G, Pizzardi G, Calio' F, Pacilè MA, Masci F, et al. (2016) Outcome of inferior vena cava and noncaval venous leiomyosarcomas. Surgery 159: 613-620. 
Citation: Stramare R, Orsatti G, Attar S, Rastrelli M, Brunello A (2016) Imaging Features, Differential Diagnosis and Management of Leiomyosarcomas: Case Series and Review of the Literature. J Cancer Sci Ther 8: 084-091. doi:10.4172/1948-5956.1000397

62. Widmann G, Riedl A, Schoepf D, Glodny B, Peer S, et al. (2009) State-of-theart HR-US imaging findings of the most frequent musculoskeletal soft-tissue tumors. Skeletal Radiol 38: 637-649

63. Beaman FD, Kransdorf MJ, Andrews TR, Murphey MD, Arcara LK, et al. (2007) Superficial soft-tissue masses: analysis, diagnosis, and differential considerations. Radiographics 27: 509-523.

64. Stramare R, Gazzola M, Coran A, Sommavilla M, Beltrame V, et al. (2013) Contrast-enhanced ultrasound findings in soft-tissue lesions: preliminary results. J Ultrasound 16: 21-27.

65. Morel M, Taïeb S, Penel N, Mortier L, Vanseymortier L, et al. (2011) Imaging of the most frequent superficial soft-tissue sarcomas. Skeletal Radiol 40: 271-284

66. Murase E, Siegelman ES, Outwater EK, Perez-Jaffe LA, Tureck RW (1999) Uterine leiomyomas: histopathologic features, MR imaging findings, differential diagnosis and treatment. Radiographics 19: 1179-1197

67. Pattani SJ, Kier R, Deal R, Luchansky E (1995) MRI of uterine leiomyosarcoma. Magn Reson Imaging 13: 331-333.

68. Illuminati G, Calio' FG, D'Urso A, Giacobbi D, Papaspyropoulos V, et al. (2006) Prosthetic replacement of the infrahepatic inferior vena cava for leiomyosarcoma. Arch Surg 141: 919-924.

69. Gronchi A, De Paoli A, Dani C, Merlo DF, Quagliuolo V, et al. (2013) Preoperative chemo-radiation therapy for localised retroperitoneal sarcoma: A phase I-II study from the Italian Sarcoma Group. Eur J Cancer 50: 784-792.

70. Bonvalot S, Raut CP, Pollock RE, Rutkowski P, Strauss DC, et al. (2012) Technical considerations in surgery for retroperitoneal sarcomas: position paper from E-Surge, a master class in sarcoma surgery, and EORTC-STBSG. Ann Surg Oncol 19: 2981-2991

71. Woll PJ, Reichardt P, Le Cesne A, et al. (2012) Adjuvant chemotherapy with doxorubicin, ifosfamide, and lenograstim for resected soft-tissue sarcoma (EORTC 62931): a multicentre randomised controlled trial. Lancet Oncol 13: 1045-1054
72. Anaya DA, Lev DC, Pollock RE (2008) The role of surgical margin status in retroperitoneal sarcoma. J Surg Oncol 98: 607-610.

73. Reed NS, Mangioni C, Malmström H, Scarfone G, Poveda A, et al. (2008) Phase III randomised study to evaluate the role of adjuvant pelvic radiotherapy in the treatment of uterine sarcomas stages I and II: an european organisation for research and treatment of cancer gynaecological cancer group study (protocol 55874). Eur J Cancer 44: 808-818

74. Amankwah EK, Conley AP, Reed DR (2013) Epidemiology and therapies for metastatic sarcoma. Clin Epidemiol 5: 147-162.

75. Ducoulombier A, Cousin S, Kotecki N, Penel N (2016) Gemcitabine-based chemotherapy in sarcomas: A systematic review of published trials. Crit Rev Oncol Hematol 98: 73-80.

76. Demetri GD, Von Mehren M, Jones RL, Hensley ML, Schuetze S, et al. (2015) Efficacy and safety of trabectedin or dacarbazine for metastatic liposarcoma or leiomyosarcoma after failure of conventional chemotherapy: results of a phase III randomized multicenter clinical trial. J Clin Oncol 34: 786-793.

77. ESMO/European Sarcoma Network Working Group (2012) Soft tissue and visceral sarcomas: ESMO Clinical Practice Guidelines for diagnosis, treatment and follow-up. Ann Oncol 23:92-99

78. Frustaci S, Gherlinzoni F, De Paoli A, Bonetti M, Azzarelli A, et al. (2001) Adjuvant chemotherapy for adult soft tissue sarcomas of the extremities and girdles: results of the Italian randomized cooperative trial. J Clin Oncol 19: 1238-1247.

79. Miyajima K, Oda Y, Oshiro Y, Tamiya S, Kinukawa N, et al. (2002) Clinicopathological prognostic factors in soft tissue leiomyosarcoma: a multivariate analysis. Histopathology 40: 353-359.

80. Kraft S, Fletcher CD (2011) Atypical intradermal smooth muscle neoplasms: clinicopathologic analysis of 84 cases and a reappraisal of cutaneous "leiomyosarcoma". Am J Surg Pathol 35: 599-607

81. Choi BI, Lee WJ, Chi JG, Han JK (1990) CT manifestations of Peritoneal Leiomyosarcomatosis. AJR Am J Roentgenol 155: 799-801 